\title{
PROGNOSIS FOR DISASTERS CAUSED BY ACCIDENTS IN THE REGION OF VARNA BULGARIA
}

\author{
Romanova H. ${ }^{1}$, Radeva N. ${ }^{2}$, Marinova I. ${ }^{1}$, Marinov M. ${ }^{3}$, Bojchev B. ${ }^{4}$, Mirtchev K. ${ }^{5}$, \\ Radev R. ${ }^{3}$ \\ ${ }^{I}$ Departmet of Hygiene and Disaster Medicine, Faculty of Public Health, Medical \\ University of Varna "Prof. P. Stoyanov" \\ ${ }^{2}$ Association of Invalids - Varna \\ ${ }^{3}$ Department of Preclinical and Clinical Sciences, Medical University of Varna \\ "Prof. P. Stoyanov" \\ ${ }^{4}$ University Hospital - Varna \\ ${ }^{5}$ Department of Physiology and Pathophysiology, Medical University of Varna \\ "Prof. P. Stoyanov"
}

\begin{abstract}
Disastrous situations result from the action of natural and technological (anthropogenic) factors. The technological disasters become more common due to the considerable progress in the field of modern industrial technologies. They represent a permanently threatening potential danger for the world as a whole, for Bulgaria and for the region of Varna as well. The production capacities and the stored and used industrial toxic substances along with the natural-geographic peculiarities contributing to the polluted territory after accidents in the region of Varna were analyzed. A flexible and rapidly adapting organization of medical service in case of disasters was created.
\end{abstract}

Key words: Disaster; Industrial toxic substances; Environmental factors; Medical service in disasters; Region of Varna

\section{INTRODUCTION}

Disasters always arise from some fundamental disequilibrium between hazards in the environment and the vulnerabilities of human communities. Understanding the major factors tending to produce hazards and vulnerabilities in the future plays a key role in disaster risk management [Arnold, 2002]. The development of information and communication technologies can bring about improvements in health by better delivery of health and disaster management services to remote locations [Chandrasekhar and Ghosh, 2001]. Telecommunication infrastructures support disasters information movement among geographically dispersed locations [Cabrera et al., 2001]. Recently, a Swedish Disaster Medicine study organization named KAMEDO was established to study the events, collect useful information and identify problems relative to the practice of disaster medicine [Kulling and Lorin, 1999].

Ammonia is known as a household cleaner, but it is also used extensively in the commercial sector. The food manufacturing industry uses ammonia as a chemical coolant for refrigeration, and in agriculture ammonia is used as a fertilizer. Its extensive use leads to widespread possibility of accidental release and exposure to toxic concentrations [Weisskopf et al., 2003].

The technological disasters are a potential danger for Bulgaria and particularly for the industrialized region of Varna. That is why the objective of the present study is to elaborate prognoses for the potential risk for disastrous situations of anthropogenic nature, i.e. in case of industrial accidents in the enterprises within the region of Varna.

\section{MATERIALS AND METHODS}

The analysis of the literature sources and of the production information from several industrial enterprises in the towns of Varna and of Devnya provided data about the amounts of industrial toxic substances (ITS) stored in these enterprises. An expert evaluation of the official documents was carried out. The geographic and climatic peculiarities of this area close to the Bulgarian Black Sea coast were described with a view of the distribution of these ITS over the corresponding territory and their eventual harmful influences on the environment and the population.

\section{RESULTS AND DISCUSSION}

It was established that there exist considerable amounts of risk substances produced and stored in the region of Varna such as chlorine (500 t), nitric acid (1500 t), ammonia (150-500 t), sulfuric acid (6000 t), dichlorethane $(20000 \mathrm{t})$, and ammonium nitrate (40000 t). 
In the municipality of Varna the following firms store and make use of substances that are fire and explosion hazards for the local population and territory in the close proximity: Petrol Co. of Sofia, Varna Branch $-21470 \mathrm{~m}^{3}$ petrol derivatives; Odesos Dockyard Co. - $40 \mathrm{~m}^{3}$ /hour acetylene; Centralized Heating System Ltd of Varna $-5000 \mathrm{~m}^{3}$ petrol derivatives and $2000 \mathrm{~m} 3$ natural cries monthly. Varna Thermo-electric Power-station - 1250 t of black oil, etc.

In the municipality of Devnya the following enterprises store and make use of large amounts of ITS: Agropolychim Co - $435 \mathrm{t}$ of ammonia and $1770 \mathrm{t}$ nitric acid; Solvay Sodi Co. - $1460 \mathrm{~m}^{3}$ of ammonia water and $1280 \mathrm{~m}^{3}$ of ammonia bisulphide; Polymeri Co - storage capacities of 664 $\mathrm{t}$ of chlorine and $417 \mathrm{t}$ of dichlorethane; Devnya Thermoelectric Power-station - 3 tanks of $10000 \mathrm{~m}^{3}$ black oil each, etc.

A total of 21 enterprises and firms located mainly in the municipalities of Varna and Devnya are considered potentially dangerous for the region of Varna. A series of chemical production lines such as chlorine and chlorine compounds, dichlorethane, calcinated soda, nitrogen and phosphate fertilizers, cement, etc. are concentrated here. The production capacities and the dissemination of ITS being raw materials, intermediate, or end products play a crucial role for the degree and consequences of the eventual industrial accidents. Ammonia and chlorine both are primary ITS which can pollute large territories and cause mass intoxications among the workers and the population. During storage and/or transportation of ammonia and dichlorethane there is a potential danger of explosion and fire. There is a danger of releases of oil produces in the areas of Petrol Co. of Sofia, Varna Branch, Varna Port, the old canal in the proximity of Odesos Dockyard Co., etc.

The most large-scale focus of chemical contamination would occur in case of a chlorine release of $100 \mathrm{t}$ in the Polymeri Co. enterprise. With wind velocity of $1 \mathrm{~m} / \mathrm{sec}$, wind direction of $270^{\circ}$ (from West to East), vertical air stability (inversion), and air temperature of $20^{\circ} \mathrm{C}$, the depth of dissemination of the primary cloud will be $18 \mathrm{~km}$, that of the secondary one will be $2 \mathrm{~km}$ and the area of contamination of the primary cloud will be $38.5 \mathrm{~km}^{2}$. In this way, four villages (Konstantinovo, Zvezditsa, Topoli and Kazashko) and Varna Airport will be contaminated. Besides the agricultural plants, open water sources, air, soil, buildings and installations within the zone of the primary cloud will be polluted. The toxic chlorine cloud will remain between 2 and 5 hours.

According to the expert prognosis of Civil Defence Office of Varna, in case of ammonia release from some food manufacturing factories in Varna and initial data such as wind velocity of $1 \mathrm{~m} / \mathrm{sec}$, wind direction of $270^{\circ}$ (from West to East) vertical air stability (inversion), and air temperature of $20^{\circ} \mathrm{C}$ the following dangerous situation can emerge (Table $1)$.

Table 1. Some Pollution Patterns after Ammonia Release from Food Manufacturing Factories in Varna

\begin{tabular}{|l|c|c|c|c|}
\hline Factory name & Ammonia(t) & $\begin{array}{c}\text { Area of pollution } \\
\left(\mathrm{km}^{2}\right)\end{array}$ & $\begin{array}{c}\text { Depth of the primary } \\
\text { cloud }(\mathrm{km})\end{array}$ & $\begin{array}{c}\text { Depth of the secondary } \\
\text { cloud }(\mathrm{km})\end{array}$ \\
\hline Vitalact Co & 22 & 3.2 & 2.5 & 0.60 \\
\hline Varna Brewery Co. & 15 & 2.1 & 2.0 & 0.45 \\
\hline Dimyat Winery Co. & 5 & 1.2 & 1.1 & 0.20 \\
\hline Varna Fruit Ltd. & 4 & 1.0 & 0.9 & 0.18 \\
\hline
\end{tabular}

The distance between the plants producing ammonia and chlorine in the town of Devnya and the town of Varna is $25 \mathrm{~km}$. The time required by these ITS to reach the town of Varna after an accident in the plants is 6 hours. The danger for the population of Varna is due to the circumstance that ammonia remains in the air about half an hour while chlorine does between 2 and 5 hours. Besides the air pollution of 2-3 $\mathrm{km}^{2}$ large territories in the Western area of the town of Varna including the numerous industrial enterprises, Varna Airport and three housing estates is possible.
According to Weisskopf et al. (2003), unplanned releases of ammonia lead more often to evacuation and injury than releases of other chemicals. The authors analyze the data of the Hazardous Substances Emergency Events Surveillance system in ten USA states for 1993-1998.

Evacuation of a total of at least 40680 persons result from 537 ammonia releases, and ammonia releases lead to injury of 1434 persons.

Cyanates representing a danger for the population in case of accident are produced and stored by several industrial firms in the town of Varna (Table 2). 
Table 2. Amounts of Cyanates Produced and Stored in Some Firms in the Town of Varna

\begin{tabular}{|l|l|l|}
\hline Plant name & ITS & Amounts \\
\hline VAMO Co. & cyanogen containing waste & $25 \mathrm{t}$ \\
\hline Elcom Co. & cyanates & $7.2 \mathrm{t}$ \\
\hline Varna Shipyard Co. & cyanates & $6.8 \mathrm{t}$ \\
\hline Metal Co. & cyanogen containing waste & $3.43 \mathrm{t}$ \\
\hline
\end{tabular}

The permanent way of F-300 gas-main passing through the municipality of Varna and supplying natural gas to several objects such as Centralized Heating System Ltd of Varna, Dimyat Winery Co., Varna Brewery Co., Metal Co. and Hiat Chemical Bulgaria represents an opportunity for a dangerous industrial accident. Its course is through several buildings of temporary statute laterally to the Vladislav Varnenchik housing estate.

Catastrophes with motor vehicles such as automobile and railway cisterns transporting ITS and other TS can induce air and soil contamination, too. Recently, health consequences of soil contamination by crude oil and its products at the oil refinery at Novi Sad, Serbia, after fires [Skrbic and Miljevic, 2002] and by heavy and inorganic metals in five Serbian sites after bombardment during the war in 1999; [Skrbic, et al., 2002] were discussed.

Emergency medical measures require evacuation of the people from the focus of contamination timely gas mask usage, respiratory and cardiac resuscitation, etc.

Along with the production capacities, the environmental conditions are of importance for the consequences from the industrial accidents in a given region. Concerning the region of Varna and Devnya the lay configuration and the dynamics of air pool related with it, the degree of humidity and water exchange play the most significant role. The region presents with a typical pattern of a closed displacement and relative exceeding of flanking slopes up to 200-250 m high. It is open only to the East towards the Black Sea that facilitates the penetration of the sea influence. This territory belongs to the continentalMediterranean climatic area. The influence of the Black Sea presents with lower summer air temperatures and higher relative air humidity along with typical breeze circulation particularly expressed in summer.

The process of dissemination of ITS into the atmospheric air depends to a greatest extent on wind features. The prevailing direction and velocity of the wind is determined by the concrete synoptic conditions and by the general trends in the atmospheric transfer during the different seasons. In the town of Varna the predominant wind directions that present with a different frequency during the corresponding seasons are West, Northwest-East, and South-East while in the town of Devnya these are North, Northwest-East, and South-East. In Devnya the relative share of northern winds is considerably greater during all the seasons. The cases with silent weather surpass by more than two times these in Varna and reach their peak in October that is unfavourable for atmospheric air purification after industrial accidents.

The amounts of rainfalls, their seasonal distribution, intensity and frequency play an important role for the processes of atmospheric air purification. In Devnya the ratio between the rainfalls during the cold and the warm halfyears is of 0.80 but in Varna it is of 0.92. It is known that when this ratio is below 1.0 the seasonal distribution of the rainfalls does not favour their cleaning effect that is of importance in case of accidents. Although the relative air humidity in Devnya is lower than that in Varna, particularly during the warm half-year, the number of days with fog is greater during the longer part of the year. The comparison of the climatic conditions between Varna and Devnya reveals that these in Devnya contribute to a much lesser extent to the purification of the atmospheric air from ITS. There is a more common silent weather, a lower wind velocity, smaller number of cases with strong winds more fogs, and a smaller amount of rainfalls.

The prevention of health hazards after industrial accidents and other disasters is of utmost importance. Organisational arrangements for the public health management of major chemical incidents and their sequelae must move beyond short-term funding and market competition and must incorporate the expertise of the occupational disciplines [Palmer et al, 2000]. The complex activity of the medical health service in the region of Varna after disasters is guided by the Ministry of Health as the head of the Regional Health Centre of Varna represents the chief of all the health care institutions in the region of Varna independently of their subordination under normal work conditions and of their form of property (state or private). The structural subunits of the Hygienic and Epidemiological Inspection of Varna play a primary role for defence of the population from disasters. There exists a permanent object commission for protection of the population in case of disasters, separation and evacuation. There are special formations such as a division for intelligence work and express analysis, as well as a radiometric, chemical and microbiological laboratory. These links are prepared for sample collection and performance of examinations of the 
environment, waters and foods under incident conditions. These formations include specialists such as epidemiologists, sanitary inspectors, physicians, physicists, chemists, radiobiologists, etc.

The control by the Hygienic and Epidemiological Inspection of the environment after an accident consists in the following: i) detection (indication) of the harmful factors in the air, foods and water, etc.; ii) performance of expert evaluation of foods and drinking water; iii) prescription of guidelines for the necessary special processing in dependence on the nature and degree of contamination such as degasation, sterilization, etc.; iv) control of the special processing of the foods and water.

\section{CONCLUSIONS}

1. Disastrous situations in the region of Varna could emerge after accidents in the enterprises in the towns of Varna and Devnya.

2. The size and extent of the disaster depend on the existing production capacities - KIWIS and amounts of ITS and explosion hazards.

3. Natural and geographic peculiarities in the town of Devnya contribute to a much lesser extent than these in the town of Varna to the purification of the atmosphere from ITS.

4. In the region of Varna there exists a flexible and rapidly adapting organization of the medical service in case of disasters.

5. The Hygienic and Epidemiological Inspection of Varna organizes and performs the control of the environmental pollution on the territory of the incident.

\section{REFERENCES:}

1. Weisskopf MG., J.M. Drew, L.P. Hanrahan, H.A. Anderson, G.S. Haugh. Hazardous ammonia releases: public health consequences and risk factors for evacuation and injury United States, 1993-1998. J Occup Environ Med, 2003 Feb;45(2):197204. http://www.ncbi.nlm.nih.gov/pubmed/ 12625234

2. Arnold JL. Disaster medicine in the 21st century: future hazards, vulnerabilities, and risk. Prehosp. Disaster Med. 2002 JanMar;17(1):3-11. http:// www.ncbi.nlm.nih.gov/pubmed/12357562

3. Skrbic B., J. Novakovic, N. Miljevic. Mobility of heavy metals originating from bombing of industrial sites. J Environ Sci Health Part A Tox Hazard Subst Environ Eng. 2002 Jan;37(1):7-16. http:// www.ncbi.nlm.nih.gov/pubmed/11846270

4. Skrbic B., N. Miljevic. An evaluation of residues at an oil refinery site following fires. J Environ Sci Health Part A Tox Hazard Subst Environ Eng. 2002; 37(6):1029-1039. http:// www.ncbi.nlm.nih.gov/pubmed/12090277

5. Cabrera M.F., M.T. Arredondo, A. Rodriguez, J. Quiroga. Mobile technologies in the management of disasters: the results of a telemedicine solution. Proc AMIA Symp., 2001, pp. 86-89. http:// www.ncbi.nlm.nih.gov/pubmed/11825159

6. Chandrasekhar C.P., J. Ghosh. Information and communication technologies and health in low income countries: the potential and the constraints. Bull World Health Organ, 2001 79(9):850855. DOI: 10.1590/S0042-96862001000 $900010 \quad$ (http://www.scielosp.org/ scielo.php?pid=S0042-96862001000 900010\&script $=$ sci_abstract )

7. Palmer S.R., H. Rees, G. Coleman. Major chemical incidents: bridging the occupational-public health gap. Occup Med (London), 2000, 50: 221-225. http:// www.ncbi.nlm.nih.gov/pubmed/10912371

8. Kulling PE, H. Lorin. KAMEDO - a Swedish Disaster Medicine Study organization. Prehos. Disaster Med., 1999 Jan-Mar;14(1):18-26. http:// www.ncbi.nlm.nih.gov/pubmed/10537595

9. Mardirosyan G. Ecologic catastrophes. Vanesa Publishing House, Sofia, 1995 (in Bulgarian).

10. Popzaharieva B. Disaster medicine. Znanie Publishing House, Stara Zagora, 1995 (in Bulgarian).

11. Romanova H. Disastrous situations and medical service. Varna, 1991 (in Bulgarian).

12. Gambihler R. Metro-Katastrophe vom 28.10.1995 in Bam Aserbeischan. Mottwill, 1997.

13. Munro B.N., S.S. Talmage, G.D. Griffin, L.C. Waters, A.P. Watson, J.F. King, V. Hauschild. The sources, fate, and toxicity of chemical warfare agent degradation products. Environ Health Perspect., 1999 Dec; 107(12): 933-974. http:// www.ncbi.nlm.nih.gov/pmc/articles/ PMC1566810

\author{
Address for correspondence: \\ Radko Zlatkov Radev \\ Department of preclinical and clinical medicine, Medical University of Varna "Prof. \\ P. Stoyanov" \\ E-mail: pathophysiology@mu-varna.bg
}

